SVERIGES RIKSBANK

WORKING PAPER SERIES

160

$2 \pi 9$

reg

管

SVERIGES

RIKSBANK

\title{
Why Are Long Rates Sensitive to Monetary Policy
}

Tore Ellingsen and UIf Söderström

APRIL 2004 
WORKING PAPERS ARE OBTAINABLE FROM

Sveriges Riksbank • Information Riksbank • SE-103 37 Stockholm Fax international: +4687870526

Telephone international: +4687870100

E-mail: info@riksbank.se

The Working Paper series presents reports on matters in the sphere of activities of the Riksbank that are considered to be of interest to a wider public.

The papers are to be regarded as reports on ongoing studies and the authors will be pleased to receive comments.

The views expressed in Working Papers are solely the responsibility of the authors and should not to be interpreted as reflecting the views of the Executive Board of Sveriges Riksbank. 


\title{
Why Are Long Rates Sensitive to Monetary Policy?
}

\author{
Tore Ellingsen Ulf Söderström* \\ Sveriges Riksbank Working Paper Series \\ No. 160 \\ April 2004
}

\begin{abstract}
We use a quantitative model of the U.S. economy to analyze the response of long-term interest rates to monetary policy, and compare the model results with empirical evidence. We find that the strong and time-varying yield curve response to monetary policy innovations found in the data can be explained by the model. A key ingredient in explaining the yield curve response is central bank private information about the state of the economy or about its own target for inflation.
\end{abstract}

Keywords: Term structure of interest rates, yield curve, central bank private information, excess sensitivity.

JEL Classification: E43, E52.

*Ellingsen: Department of Economics, Stockholm School of Economics, Box 6501, 11383 Stockholm, Sweden, tore.ellingsen@hhs.se. Söderström: Department of Economics and IGIER, Università Bocconi, Via Salasco 5, 20136 Milano, Italy, ulf.soderstrom@uni-bocconi.it. We are grateful for comments from Geert Bekaert, Carlo Favero, Refet Gürkaynak, Glenn Rudebusch and seminar participants at Università Bocconi, Sveriges Riksbank, University of St. Gallen, the EDGE Summer School in Aix-en-Provence, September 2003, and the AEA meetings in San Diego, January 2004. The views expressed in this paper are solely the responsibility of the authors and should not be interpreted as reflecting the views of the Executive Board of Sveriges Riksbank. 


\section{Introduction}

In Ellingsen and Söderström (2001) we developed a simple theory of how the monetary policy actions of an optimizing central bank affect the term structure of interest rates. The model rationalizes shifts in the yield curve as changes in economic fundamentals (inflation or output), and it rationalizes rotations in the yield curve as changes in the preferences of the monetary policymakers. According to the theory, observed monetary policy interventions affect the yield curve inasmuch as market participants draw inferences about fundamentals or about the policy maker's preferences from the intervention.

An econometric test reported in Ellingsen and Söderström (2003) offers support for the model's main qualitative predictions: after policy innovations interpreted by market participants as being due to economic fundamentals, long rates move in the same direction as short rates, while after innovations interpreted as being due to shifts in the policymaker's preferences, long and short rates move in opposite directions. However, due to the theoretical model's small number of parameters it cannot quantitatively match the yield curve movements that we observe. In the current paper we therefore generalize the model by allowing more parameters to differ from zero. At the same time, we make the model more precise by using estimated parameters that reflect the postwar U.S. experience. The properties of the quantitative model are compared with actual yield curve movements, with an emphasis on the response of long rates to changes in the short-term interest rate. ${ }^{1}$

When there is full information, so private agents can observe shocks and central bank preferences, long-term interest rates in our macro model hardly respond at all to innovations in monetary policy, while empirical studies suggest that the response is substantial. Thus, observed interest rates seem to be excessively sensitive to monetary policy innovations. However, when we introduce private information, so private agents cannot observe either the state of the economy or the inflation target of the central bank, long rates in our model respond strongly to monetary policy moves and the yield curve response depends on the information content of the policy innovation, as in our simple theoretical model. Furthermore, the magnitudes of the yield curve response are similar to those found in the data.

The excess sensitivity puzzle has recently been thoroughly studied by Gürkaynak

\footnotetext{
${ }^{1}$ Although we here focus primarily on the response of the yield curve to observed changes in the central bank's interest rate, our analysis bears equally on yield curve movements on days when there are no policy changes. On these days movements are driven by expectations of the central bank's future reaction to the observed economic developments.
} 
et al. (2003), who focus on the response of forward interest rates to both macroeconomic announcements and monetary policy innovations. Their model can account for the observed negative response of long-term forward rates to monetary policy innovations by allowing for central bank private information about the inflation target. However, they are not able to explain the strong positive response of long-term yields to monetary policy found in most empirical studies nor the time-varying response of long rates to monetary policy. In contrast, our model is able to account for the large and time-varying response of long rates to monetary policy by allowing also for central bank private information about the state of the economy, as in Romer and Romer (2000).

Our paper is organized as follows. We begin in Section 2 by illustrating the excess sensitivity puzzle. In Section 3 we briefly summarize the existing theoretical and empirical literature on the effects of central bank private information on the relationship between monetary policy and the yield curve. Section 4 presents our main results, and Section 5 provides a sensitivity analysis with respect to key parameters in the model. Section 6 concludes.

\section{Monetary policy and the yield curve: Empirical estimates and predictions from a macro model}

As an illustration of the relationship between monetary policy and the yield curve, Figure 1 shows the estimated daily response of market interest rates in the U.S. (up to 10 years' maturity) to unexpected changes in the Federal Reserve's policy rate, measured as the daily change in the three-month T-bill rate. ${ }^{2}$ The figure shows the estimated slope coefficients $b_{n}$ (with two standard-error confidence intervals) from the regression

$$
\Delta i_{t}^{n}=a_{n}+b_{n} \Delta i_{t}^{3 \mathrm{~m}}+v_{t}^{n}
$$

where $\Delta i_{t}^{n}$ is the change in the $n$-maturity interest rate on day $t$ and $\Delta i_{t}^{3 \mathrm{~m}}$ is the corresponding change in the three-month rate. This regression is estimated over all days when the Federal Reserve's target for the federal funds rate was changed from October 1988 to December 2001. During this period, there is a clear positive relationship between interest rates of all maturities and the three-month rate: a one

\footnotetext{
${ }^{2}$ We use the change in the three-month rate to measure policy innovations rather than expectations derived from the federal funds futures market as these are strongly influenced by the timing of policy moves. For similar reasons, Rigobon and Sack (2002) use the rate on three-month eurodollar futures contracts.
} 
percentage point increase in the three-month rate is on average associated with an increase in the 5-year rate of 51 basis points and in the 10-year rate of 29 basis points. $^{3}$

This strong response of long-term interest rates to monetary policy innovations is typically difficult to replicate using standard macro models (see also Gürkaynak et al., 2003). Throughout this paper we will evaluate the yield curve response to monetary policy using the quantitative New-Keynesian model estimated by Rudebusch (2002) on quarterly U.S. data, extended with a term structure relationship to determine the yield curve. Inflation $\left(\pi_{t}\right)$ and the output gap $\left(y_{t}\right)$ are thus assumed to follow ${ }^{4}$

$$
\begin{aligned}
& \pi_{t}=\mu_{\pi} \mathrm{E}_{t-1} \bar{\pi}_{t+3}+\left(1-\mu_{\pi}\right) \sum_{j=1}^{4} \alpha_{\pi j} \pi_{t-j}+\alpha_{y} y_{t-1}+\varepsilon_{t}, \\
& y_{t}=\mu_{y} \mathrm{E}_{t-1} y_{t+1}+\left(1-\mu_{y}\right) \sum_{j=1}^{2} \beta_{y j} y_{t-j}-\beta_{r}\left[i_{t-1}-\mathrm{E}_{t-1} \bar{\pi}_{t+3}\right]+\eta_{t} .
\end{aligned}
$$

Here, $\pi_{t} \equiv 400\left(\log P_{t}-\log P_{t-1}\right)$ is the annualized quarterly rate of inflation; $\bar{\pi}_{t} \equiv$ $1 / 4 \sum_{j=0}^{3} \pi_{t-j}$ is the average four-quarter inflation rate; $i_{t}$ is the quarterly (annualized) interest rate; $y_{t}$ is the output gap (the percentage deviation of real GDP from "potential"); and the supply and demand shocks $\varepsilon_{t}$ and $\eta_{t}$, are i.i.d. with mean zero and constant standard deviation $\sigma_{\varepsilon}, \sigma_{\eta}$.

To close the model, we assume that the central bank chooses a path for the shortterm interest rate $i_{t}$ to minimize (under discretion) a standard objective function:

$$
\min _{\left\{i_{t}\right\}} \operatorname{Var}\left[\bar{\pi}_{t}-\pi_{t}^{*}\right]+\lambda \operatorname{Var}\left[y_{t}\right]+\nu \operatorname{Var}\left[\Delta i_{t}\right]
$$

where $\pi_{t}^{*}$ is a time-varying target for inflation, which follows

$$
\pi_{t}^{*}=\rho \pi_{t-1}^{*}+\zeta_{t}
$$

where $0 \leq \rho<1$ and $\zeta_{t}$ is an i.i.d. disturbance with standard deviation $\sigma_{\zeta}$. The central bank thus acts to minimize the weighted variances of inflation, the output gap, and the change in the interest rate. Finally, long-term interest rates are assumed

\footnotetext{
${ }^{3}$ Similar estimates have been found for other time periods and for other countries, and using other techniques. For example, for U.S. data, Evans and Marshall (1998, 2002) use identified VARs, Rigobon and Sack (2002) use a heteroskedasticity-based estimator, and Kuttner (2001) uses policy surprises calculated from prices of federal funds futures contracts. For other countries, see Battellino et al. (1997) for Australia; Buttiglione et al. (1997) for Italy; and Lindberg et al. (1997) for Sweden.

${ }^{4}$ While the main specification of Rudebusch (2002) allows for forward-looking behavior only in the determination of inflation, we also introduce forward-looking behavior in the output equation.
} 
Table 1: Parameter values

\begin{tabular}{lrlrlc}
\hline \hline \multicolumn{2}{c}{ Inflation } & \multicolumn{3}{c}{ Output gap } & \multicolumn{2}{c}{ Monetary policy } \\
\hline$\mu_{\pi}$ & 0.29 & $\mu_{y}$ & 0.22 & $\lambda$ & $\{0.1,0.5,1.0\}$ \\
$\alpha_{\pi 1}$ & 0.67 & $\beta_{y 1}$ & 1.15 & $\nu$ & $\{0.1,0.5\}$ \\
$\alpha_{\pi 2}$ & -0.14 & $\beta_{y 2}$ & -0.27 & $\rho$ & 0.95 \\
$\alpha_{\pi 3}$ & 0.40 & $\beta_{r}$ & 0.09 & & \\
$\alpha_{\pi 4}$ & 0.07 & $\sigma_{\eta}$ & 0.833 & & \\
$\alpha_{y}$ & 0.13 & & & & \\
$\sigma_{\varepsilon}$ & 1.012 & & & & \\
\hline
\end{tabular}

Note: Inflation and output parameters estimated by Rudebusch (2002) on quarterly U.S. data, 1968Q3-1996Q4, except for $\mu_{y}$ which is estimated by Fuhrer and Rudebusch (2002) on quarterly U.S. data, 1966Q1-2000Q4.

to be determined by the expectations hypothesis. Thus, the interest rate on a discount bond of maturity $n$ is given by

$$
i_{t}^{n}=\frac{1}{n} \sum_{s=0}^{n-1} \mathrm{E}_{t} i_{t+s}+\xi_{t}^{n}
$$

where $\xi_{t}^{n}$ is the term premium at time $t$ for maturity $n$, assumed to be independent of monetary policy and the supply and demand shocks.

To parameterize the model we take the values of the $\alpha$ and $\beta$ parameters, $\mu_{\pi}$, and the standard deviations for the shocks $\sigma_{\varepsilon}, \sigma_{\eta}$ estimated by Rudebusch (2002). For $\mu_{y}$, Fuhrer and Rudebusch (2002) obtain a range of estimates from 0 to 0.45 , and we choose an intermediate value of 0.22 . We use three values for the preference for output stabilization, $\lambda \in\{0.1,0.5,1.0\}$, and two values for the preference for interest rate smoothing, $\nu \in\{0.1,0.5\}$. The inflation target is assumed to be very persistent around its long-run level, with $\rho=0.95$. Table 1 summarizes these parameter values. Section 5 below provides a sensitivity analysis with respect to the free parameters in the model; $\lambda, \nu$, and $\rho$.

To see how market interest rates are affected by monetary policy in this model, Figure 2 shows the response of the policy rate $i_{t}$ over time and the contemporaneous response of the yield curve to an unexpected one percentage point increase in the policy rate, after which policy is expected to follow the optimal rule. ${ }^{5}$ It is immediately clear that the yield curve response in Figure 2 does not match the

\footnotetext{
${ }^{5}$ This interest rate disturbance is not part of the model, since the interest rate is assumed to be set optimally. Nevertheless, an artificial interest rate shock can be constructed by assuming that the interest rate is unexpectedly raised by one percentage point for one period, and that the system follows the reduced form afterwards. See Appendix B for details.
} 
estimated response in Figure 1 for any values of the preference parameters $\lambda$ or $\nu .{ }^{6}$ In the model, short-term rates respond strongly to the policy innovation, but as monetary policy is expected to return to a neutral stance relatively quickly (with some undershooting), interest rates above three years' maturity hardly respond at all. While the estimated response of the three-year rate in Figure 1 is around 60 basis points (with a confidence interval from 40 to 80 basis points), the response in the model is below two basis points. Thus, the estimated response coefficients in Figure 1 seem unlikely to be due only to market participants revising the expected path of the short rate after unexpected changes in the policy stance that are not related to any other changes in the economy or in central bank behavior.

\section{Monetary policy with private information: Theory and empirical evidence}

Romer and Romer (2000) offer one potential explanation for the strong positive response of long-term rates to policy innovations: if the Fed possesses private information about the development of inflation, unexpected changes in the policy rate reveal information about the future path of inflation. As the Fed unexpectedly tightens policy, inflation expectations are revised upwards, leading to a stronger response of long rates than under symmetric information. Romer and Romer (2000) also find empirical evidence that the Federal Reserve has private information about the future path of inflation: Federal Reserve inflation forecasts are vastly superior to those of private forecasters. ${ }^{7}$

At the same time, it is well known that the average response shown in Figure 1 hides the fact that on many occasions long-term interest rates actually fall in response to an unexpected policy tightening. Noting that monetary policy in a typical macro model is a linear function of observed inflation and output where the coefficients are related to the central bank's preferences, Ellingsen and Söderström (2001) suggest that innovations in the central bank interest rate can reveal information of two types: information about the development of the economy and information about the preferences of the central bank.

Using a very simple macro model due to Svensson (1997), Ellingsen and Söderström

\footnotetext{
${ }^{6}$ Similar results are obtained if using a Taylor-rule specification for monetary policy.

${ }^{7}$ This finding is supported by evidence reported by Peek et al. $(1999,2003)$ that the Fed's access to confidential bank supervisory data can be used to improve on inflation forecasts. On the other hand, Faust et al. (2002) do not find support for the hypothesis that the Fed has private information about either inflation or GDP.
} 
(2001) find that the yield curve response to monetary policy innovations depends crucially on the interpretation of bond market participants of the reasons behind the policy move. If the policy move is interpreted to reveal information about the state of the economy ("endogenous policy"), interest rates of all maturities move in the same direction as the policy interest rate. If, on the other hand, bond market participants view the policy move as driven by changes in the central bank's preferences ("exogenous policy"), long and short rates move in opposite directions.

The intuition behind these results is straightforward. When supply or demand shocks cannot be directly observed, any unanticipated increase in the central bank's policy rate is interpreted as a response to an unobserved inflationary shock. As the central bank is expected to counteract this inflationary impulse by tightening policy for some time, interest rates of all maturities increase as market participants update their expectations of the future path of the short rate. If, on the other hand, shocks are observable, but central bank preferences or objectives are not, an unanticipated tightening of policy is interpreted as a shift to a more inflation averse policy. Such a shift will imply a period of tighter policy than previously expected, but a quicker return to a neutral stance. Thus, short-term rates will increase in response to the policy innovation, while longer rates fall.

In Ellingsen and Söderström (2003) we test these theoretical predictions by classifying policy moves in the U.S. as endogenous or exogenous using reports in the Wall Street Journal. The results are illustrated in Figure 3. Panel (a) reiterates the results from Figure 1, showing the estimated response of the yield curve to changes in the three-month T-bill rate (our measure of policy innovations) on all days when the Federal Reserve's target for the federal funds rate was changed from October 1988 to December 2001. ${ }^{8}$ Panels $(b)$ and $(c)$ show the estimated coefficients from the two subsamples: policy events classified as endogenous and exogenous, respectively. After endogenous policy innovations in panel $(b)$, interest rates of all maturities are positively related to the short rate, and all coefficients up to 10 years' maturity are significant at the 1\%-level. After exogenous innovations in panel $(c)$, the response of short rates is still significantly positive, while that of interest rates of 5 years' maturity and longer is negative, although typically not significant. ${ }^{9}$

However, there is likely to be some new information about the economy released also on the days classified as exogenous. Therefore, Ellingsen and Söderström (2003)

\footnotetext{
${ }^{8}$ The estimation results in panel $(a)$ are not reported in Ellingsen and Söderström (2003); detailed results are available upon request.

${ }^{9}$ The response of the 10-year rate is significant at the $10 \%$-level and that of the 30-year rate (not shown in the figure) is significant at the $5 \%$-level.
} 
adjust the estimates from exogenous policy days to identify the truly exogenous component. These adjusted estimates are shown in panel $(d)$ of Figure 3. Now all interest rates of 5 years' maturity and longer are negatively related to the short rate, and the coefficients are significant at the 5\%-level.

These empirical results thus give strong support for our theoretical predictions: after policy moves classified as endogenous, interest rates of all maturities tend to move in the same direction, but after moves classified as exogenous, long and short rates move in opposite directions. ${ }^{10}$ Furthermore, as emphasized by Romer and Romer (2000), central bank private information may also lead to a stronger yield curve response to monetary policy moves than under symmetric information, as these moves reveal information about economic fundamentals. The next section investigates whether introducing private information in the quantitative macro model will enable us to explain the large and time-varying response of the yield curve to monetary policy.

\section{Private information and monetary policy in the macro model}

When the central bank is seen to possess private information, market participants will try to infer this information from the observed policy moves. We therefore begin by considering the response of monetary policy and the yield curve to observable shocks to inflation, the output gap and the central bank preferences. We then analyze the response of the yield curve to monetary policy when these shocks are unobservable.

While in Ellingsen and Söderström (2001) we model private information about the central bank's preferences in terms of the weight on output stabilization, $\lambda$, we here primarily focus on an alternative model where the preference parameters are known (and constant), but the inflation target $\pi_{t}^{*}$ is unobservable to private agents. ${ }^{11}$ While the two versions of the model give similar qualitative results, their quantitative

\footnotetext{
${ }^{10}$ Peersman (2002) conducts an alternative test of our theory, identifying changes in monetary policy preferences as well as changes in economic conditions using a structural VAR estimated on monthly German data. Comparing the yield curve movement following a shock to policy preferences to yield curve movements following other economic shocks, his analysis unambiguously supports the theory. In particular, 3-month and 10-year interest rates move in opposite directions following a shock to policy preferences.

${ }^{11}$ Gürkaynak et al. (2003) develop a similar idea, but instead assume that the inflation target follows

$$
\pi_{t}^{*}=\pi_{t-1}^{*}+\theta\left(\bar{\pi}_{t-1}-\pi_{t-1}^{*}\right)+\zeta_{t},
$$
}


predictions differ in some dimensions, and we discuss the alternative scenario when $\lambda$ is unobservable in Section 4.4. Throughout we will use three different values for the weight on output stabilization $(\lambda \in\{0.1,0.5,1.0\})$ and a small weight on interest rate smoothing $(\nu=0.1)$.

\subsection{The interest rate response to observable shocks}

Figure 4 shows the policy response over time to the three shocks in the model: a positive supply shock (to inflation), a positive demand shock (to output), and a negative shock to the inflation target. After both supply and demand shocks, the central bank responds by tightening monetary policy to stabilize inflation and the output gap and then gradually returning to a neutral policy stance. Intuitively, a larger weight on output stabilization (a larger $\lambda$ ) leads to a smaller (but more persistent) response to supply shocks and a larger (and less persistent) response to demand shocks. ${ }^{12}$

A negative shock to the inflation target leads to a brief period of tight policy, as inflation is brought down to the new lower target level. Eventually, the lower inflation target leads to a lower short-term nominal interest rate, and a long period of interest rates below the initial level before the inflation target slowly reverts back to its long-run level (normalized to zero). A larger weight on output stabilization leads to smaller movements in the short-term interest rate as inflation is reduced more gradually.

Figure 5 shows the implied contemporaneous response of the yield curve to the three shocks, when these shocks are observable to private agents. Because supply and demand shocks lead to a long period of higher short rates, yields of all maturities increase in response to such shocks. Note, however, that the yield curve response often does not decline monotonically with maturity. In some cases the policy response is hump-shaped with a maximum effect after two to four quarters, making one-year yields respond more strongly than the short rate. This is due to the weight on interest rate smoothing: without interest rate smoothing $(\nu=0)$, the maximum effect on policy is instantaneous, but also implausibly large (three to

and private agents' estimate of the inflation target follows

$$
\hat{\pi}_{t}^{*}=\hat{\pi}_{t-1}^{*}+\theta\left(\bar{\pi}_{t-1}-\hat{\pi}_{t-1}^{*}\right)-\kappa\left(i_{t}-\hat{\imath}_{t}\right),
$$

where $\kappa$ is the Kalman gain on deviations of the interest rate from agents' expectations based on their prior estimate of $\pi_{t}^{*}$.

${ }^{12}$ This is in contrast to the simple model used in Ellingsen and Söderström (2001), where the response to both supply and demand shocks is decreasing in $\lambda$. 
eight percentage points).

After a shock to the inflation target, on the other hand, short rates increase, but long rates fall, as the lower inflation target eventually leads to a lower level of the short rate. Thus, when all shocks are observable, different shocks will have different impact on the yield curve. While supply and demand shocks move all interest rates in the same direction, shocks to the inflation target move long and short rates in opposite directions.

\subsection{Private information: The yield curve response to monetary policy}

Under full information monetary policy and the yield curve respond to the same underlying shocks, and the yield curve does not respond to monetary policy actions per se. When the central bank has private information about these shocks, on the other hand, changes in monetary policy will reveal information about the underlying shocks. Therefore the yield curve will respond to any unexpected changes in monetary policy as market participants revise their expectations about the future path of policy.

To make things simple, we will assume that the central bank possesses private information only about one shock at a time, while the other shocks are observable to all agents. Because market participants know which shock the central bank is responding to, but not its size, it is straightforward to infer the realization of the unobservable shock from the change in the short rate. While this is a strong simplifying assumption, our study of newspaper reports after policy changes in the U.S. suggests that market participants often have a clear idea about the underlying reasons behind policy moves.

Figure 6 shows how the yield curve responds to unexpected changes in monetary policy that are due to the three shocks in the model, when these shocks are unobservable. $^{13}$ In panels $(a)$ and $(b)$, when an unexpected change in policy is due to supply or demand shocks, interest rates of all maturities increase as market participants revise their expectations about future policy. In these cases, an unexpected policy tightening is interpreted as the response to an inflationary shock, which will lead to a period of higher interest rates than usual. These yield curve responses to monetary policy innovations are also considerably larger than under symmetric information, as shown in Figure 2.

Panel $(c)$ of Figure 6 shows the yield curve response to an unexpected change in

\footnotetext{
${ }^{13}$ The Figure shows how interest rates of each maturity respond to a one unit increase in the short rate, i.e., $d i_{t}^{n} / d i_{t}$, where $d i_{t}$ and $d i_{t}^{n}$ are taken from Figure 5.
} 
monetary policy that is due to a change in the central bank's unobservable inflation target. Now short-term interest rates move in the same direction as the policy rate, but long-term interest rates move in the opposite direction. A positive policy surprise thus leads to higher short rates but lower long rates, as market participants expect the central bank to lower the short rate in the long run (see Figure $4 c$ ). Furthermore, long rates fall substantially after an unexpected policy tightening: a one percentage point innovation in policy leads to a decrease in the 10-year rate by 20-25 basis points. ${ }^{14}$

Thus, the main results derived in Ellingsen and Söderström (2001) continue to hold in this more richly parameterized model, estimated on U.S. data: After endogenous policy innovations (due to supply or demand shocks) all interest rates move in the same direction, while after exogenous innovations (due to shifts in the inflation target), long and short rates move in opposite directions.

\subsection{Quantitative results}

To see how the yield curve response in the model compares with the empirical evidence, Figure 7 shows the yield curve response in the model from Figure 6 (with $\lambda=1.0)$ along with the estimated responses in panels $(b)-(c)$ of Figure 3. After supply shocks and shocks to the inflation target in panels $(a)$ and $(c)$ of Figure 7 , the model responses are very similar to the estimated responses for all maturities. The response of the 10-year rate is around 0.3 after supply shocks and -0.25 after inflation target shocks. After demand shocks, however, there is some evidence of excess sensitivity, in particular for medium-term rates where the model response is significantly lower than the estimated response. For the 10-year rate, the estimated coefficient is 0.33 , while the model response is closer to 0.1 , although this is still within the $95 \%$ confidence intervals around the estimated response. The combined impression from Figure 7, nevertheless, is that our model with central bank private information is very successful in matching the estimated response of the yield curve to monetary policy.

\subsection{Unobservable central bank preferences}

Although we have chosen to focus on the case where the central bank preference parameters are known to the public but the inflation target is not, for many coun-

\footnotetext{
${ }^{14}$ Although the quantitative response of long rates depends on the persistence of the inflation target, assumed here to be $\rho=0.95$, Section 5 shows that the response is negative also for very small values of $\rho$.
} 
tries the opposite situation seems to be more relevant. Many central banks have announced their preferred target level for inflation, while the relative weights on inflation and output stabilization remain unobservable. Thus, in this section we briefly discuss the case of a known and constant inflation target, but an unobservable preference for output stabilization, $\lambda$. (We continue to assume that the weight on interest smoothing is observable and constant at $\nu=0.1$.)

In this case, the public observes the shocks hitting the economy, and if the central bank responds differently than expected, this is interpreted as a change in the central bank preferences. (Note that in order for preference changes to have any effect on interest rates, the economy must be away from steady state.) This inferred shift in the central bank preferences leads to a revision of the expected path of future interest rates, and thus the yield curve moves. Using the interest rate response to supply and demand shocks under different values of $\lambda$ shown in Figure 5, we can calculate how the yield curve responds to such unanticipated changes in monetary policy.

Panels $(a)$ and $(b)$ of Figure 8 show the contemporaneous yield curve response to supply and demand shocks for different values of $\lambda$, taken from Figure 5. Panels $(c)$ and $(d)$ show how the yield curve responds to unexpected movements in the short rate due to a change in $\lambda$ after supply and demand shocks. ${ }^{15}$ For instance, when market participants have observed a supply shock, but the central bank responds by raising the interest rate more aggressively than expected, market participants infer that $\lambda$ has decreased, and short rates increase while long rates fall (see Panel $(a)$ ). Panel $(c)$ shows how this response translates into a relationship between the yield curve and the short-term policy rate.

Qualitatively, after a supply shock the relationship between the yield curve and the policy rate is similar to that after an unobserved inflation target shock in Figure $6 c$, but now the effects are much larger. Because a given change in $\lambda$ has a rather small effect on the short-term policy rate, but a relatively large effect on longer rates, the response of long rates to the short rate is very large for most maturities.

However, after a demand shock the pattern is different. Because a more inflation averse central bank (with a lower $\lambda$ ) responds less aggressively to demand shocks both in the short and long run (but not in the medium run, see Figure $4 b$ ), interest

\footnotetext{
${ }^{15}$ The graphs show how the interest rate for each maturity changes in response to a one unit change in the short-term interest rate when the central bank changes its $\lambda$, e.g.,

$$
\left(\left.d i_{t}^{n}\right|_{\lambda=0.5}-\left.d i_{t}^{n}\right|_{\lambda=0.1}\right) /\left(\left.d i_{t}\right|_{\lambda=0.5}-\left.d i_{t}\right|_{\lambda=0.1}\right),
$$
}

where $d i_{t}$ and $d i_{t}^{n}$ are taken from Figure 5. 
rates of all maturities in Panel $(b)$ of Figure 8 repond less. Thus a move to a more inflation averse central bank would make short and long rates move in the same direction (but medium-term rates would move in the opposite direction), with a smaller effect on longer maturities.

\section{$5 \quad$ Sensitivity analysis}

Most of the parameters in our model are taken from the empirical estimates by Rudebusch (2002) and Fuhrer and Rudebusch (2002). In addition to these, there are three free parameters which have proven difficult to estimate precisely: the weights on output stabilization $(\lambda)$ and interest rate smoothing $(\nu)$ in the central bank's objective function and the degree of persistence of the inflation target $(\rho)$. This section will show how sensitive our results are to changes in these parameters.

Figures 9 and 10 show the yield curve response to monetary policy after unobservable supply or demand shocks, respectively, for different values of $\lambda$ and $\nu$. (This response does not depend on the persistence in the inflation target.) The responses are similar for all parameter values, except for the case when there is no interest rate smoothing in panel $(a)$. As mentioned above, when there is no interest rate smoothing the yield curve response decreases monotonically with maturity, and there is a smaller effect on long-term interest rates. However, this case also leads to very high volatility in the short-term interest rate, which is contrary to the empirical evidence. ${ }^{16}$

Allowing for more interest rate smoothing leads to a larger hump-shaped response of the yield curve, and the response of medium-term yields is typically larger than the empirical estimates in Figure 3. However, the response of long-term interest rates is often close to the empirical estimates, regardless of the value of $\lambda$ or $\nu$. In particular, the yield curve response to endogenous policy changes is positive for all maturities.

Figure 11 shows how the response to exogenous policy moves varies with the weight on interest rate smoothing $(\nu)$ and the persistence in the inflation target $(\rho)$. (Changes in the weight on output stabilization, $\lambda$, have virtually no effect on these responses, so we set $\lambda=1.0$.) Again, the case with $\nu=0$ leads to very small responses for medium- and long-term interest rates, while the responses for $\nu>0$ are qualitatively very similar: short rates always respond in the same direction as the

\footnotetext{
${ }^{16}$ Estimates of central bank objective functions typically obtain a large degree of interest rate smoothing; see, e.g., Dennis (2001) or Söderström et al. (2003).
} 
policy innovation while long rates always respond in the opposite direction. Larger values of $\nu$ leads to larger responses for all maturities: short rates increase more and long rates decrease more.

When the inflation target is not very persistent (so $\rho$ is small), long rates hardly respond at all to the policy innovation (for any value of $\nu$ ), as long-term inflation expectations do not change much. To match the estimated response in Figure 3, we therefore need a fairly persistent inflation target, with $\rho>0.8$. However, also with very little persistence in the inflation target, the response of the long-term yields fall inside the estimated confidence bands. Finally, in the extreme case when the inflation target follows a random walk (so $\rho=1$ ), and shocks to the inflation target are permanent, long-term interest rates respond very strongly to the policy innovation.

This analysis shows that our results concerning the response of long-term interest rates to monetary policy innovations (both endogenous and exogenous) are not very sensitive to the free parameters in the model: after endogenous innovations long rates increase, and after exogenous innovations long rates fall, and the responses are (almost) always inside the estimated confidence intervals in Figure 3. For mediumterm interest rates, the response depends strongly on the degree of interest rate smoothing: without interest rate smoothing, medium-term rates do not respond as strongly as in the data, and with a large degree of interest rate smoothing, mediumterm rates respond more strongly than in the data.

\section{Final remarks}

Few would deny that monetary policy has a major impact on the bond market. To our knowledge, this is nonetheless the first paper linking a quantitative model of an optimizing central bank to observed variations in the term structure of interest rates.

It has often been noted that the response of long-term interest rates to monetary policy innovations differs from occasion to occasion: sometimes long rates move in the same direction as the policy innovation, sometimes they move in the opposite direction. Most models of monetary policy cannot account for this puzzling behavior of long-term interest rates. In our previous work, we have shown that such a behavior is easily explained in a model where the central bank has private information about economic shocks and its own preferences or targets.

The analysis in this paper has confirmed this behavior in a quantitative model 
of the U.S. economy. More importantly, we here show that the model's responses are closely in line with empirical estimates of the yield curve response to monetary policy. Furthermore, this result is not very sensitive to the free parameters in our model. Thus, our findings suggest that central bank private information causes the strong impact of monetary policy on long-term interest rates. 


\section{A Model appendix}

\section{A.1 The state-space representation}

To write this model on state-space form, lead (2) and (3) one period:

$$
\begin{aligned}
\pi_{t+1}= & \frac{\mu_{\pi}}{4} \mathrm{E}_{t}\left[\pi_{t+1}+\pi_{t+2}+\pi_{t+3}+\pi_{t+4}\right] \\
& +\left(1-\mu_{\pi}\right)\left[\alpha_{\pi 1} \pi_{t}+\alpha_{\pi 2} \pi_{t-1}+\alpha_{\pi 3} \pi_{t-2}+\alpha_{\pi 4} \pi_{t-3}\right]+\alpha_{y} y_{t}+\varepsilon_{t+1}, \\
y_{t+1}= & \mu_{y} \mathrm{E}_{t} y_{t+2}+\left(1-\mu_{y}\right)\left[\beta_{y 1} y_{t}+\beta_{y 2} y_{t-1}\right] \\
& -\beta_{r}\left[i_{t}-\frac{1}{4} \mathrm{E}_{t}\left(\pi_{t+1}+\pi_{t+2}+\pi_{t+3}+\pi_{t+4}\right)\right]+\eta_{t+1} .
\end{aligned}
$$

Then solve for the forward-looking variables $\mathrm{E}_{t} \pi_{t+4}$ and $\mathrm{E}_{t} y_{t+2}$ and take expectations as of period $t$ :

$$
\begin{aligned}
\frac{\mu_{\pi}}{4} \mathrm{E}_{t} \pi_{t+4}= & \left(1-\frac{\mu_{\pi}}{4}\right) \mathrm{E}_{t} \pi_{t+1}-\frac{\mu_{\pi}}{4} \mathrm{E}_{t} \pi_{t+2}-\frac{\mu_{\pi}}{4} \mathrm{E}_{t} \pi_{t+3} \\
& -\left(1-\mu_{\pi}\right)\left[\alpha_{\pi 1} \pi_{t}+\alpha_{\pi 2} \pi_{t-1}+\alpha_{\pi 3} \pi_{t-2}+\alpha_{\pi 4} \pi_{t-3}\right]-\alpha_{y} y_{t}, \\
\mu_{y} \mathrm{E}_{t} y_{t+2}+ & \frac{\beta_{r}}{4} \mathrm{E}_{t} \pi_{t+4}=\mathrm{E}_{t} y_{t+1}-\left(1-\mu_{y}\right)\left[\beta_{y 1} y_{t}+\beta_{y 2} y_{t-1}\right] \\
& +\beta_{r}\left[i_{t}-\frac{1}{4} \mathrm{E}_{t}\left(\pi_{t+1}+\pi_{t+2}+\pi_{t+3}\right)\right]
\end{aligned}
$$

and reintroduce the disturbances via the predetermined variables

$$
\begin{aligned}
\pi_{t+1} & =\mathrm{E}_{t} \pi_{t+1}+\varepsilon_{t+1}, \\
y_{t+1} & =\mathrm{E}_{t} y_{t+1}+\eta_{t+1} .
\end{aligned}
$$

Define an $\left(n_{1} \times 1\right)$ vector of predetermined state variables $\left(n_{1}=8\right)$ as

$$
x_{1 t}=\left\{\pi_{t}, \pi_{t-1}, \pi_{t-2}, \pi_{t-3}, y_{t}, y_{t-1}, i_{t-1}, \pi_{t}^{*}\right\}^{\prime},
$$

an $\left(n_{2} \times 1\right)$ vector of forward-looking jump variables $\left(n_{2}=4\right)$ as

$$
x_{2 t}=\left\{\mathrm{E}_{t} \pi_{t+3}, \mathrm{E}_{t} \pi_{t+2}, \mathrm{E}_{t} \pi_{t+1}, \mathrm{E}_{t} y_{t+1}\right\}^{\prime},
$$

and an $\left(n_{1} \times 1\right)$ vector of shocks to the predetermined variables as

$$
v_{1 t}=\left\{\varepsilon_{t}, \mathbf{0}_{3 \times 1}^{\prime}, \eta_{t}, \mathbf{0}_{2 \times 1}^{\prime}, \zeta_{t}\right\}^{\prime} .
$$

We then can write the model on its state-space representation as

$$
A_{0}\left[\begin{array}{c}
x_{1 t+1} \\
\mathrm{E}_{t} x_{2 t+1}
\end{array}\right]=A_{1}\left[\begin{array}{c}
x_{1 t} \\
x_{2 t}
\end{array}\right]+B_{1} i_{t}+v_{t+1}
$$


where

$$
v_{t+1}=\left[\begin{array}{c}
v_{1 t+1} \\
\mathbf{0}_{n 2 \times 1}
\end{array}\right],
$$

and where the coefficient matrices are

$$
\begin{aligned}
& A_{0}=\left[\begin{array}{ccccc}
\mathbf{I}_{n 1 \times n 1} & \multicolumn{5}{c}{\mathbf{0}_{n 1 \times n 2}} & \\
& \mu_{\pi} / 4 & 0 & 0 & 0 \\
& 0 & 1 & 0 & 0 \\
\mathbf{0}_{n 2 \times n 1} & 0 & 0 & 1 & 0 \\
& \beta_{r} / 4 & 0 & 0 & \mu_{y}
\end{array}\right], \\
& A_{1}=\left[\begin{array}{cccccccccccc}
0 & 0 & 0 & 0 & 0 & 0 & 0 & 0 & 0 & 0 & 1 & 0 \\
1 & 0 & 0 & 0 & 0 & 0 & 0 & 0 & 0 & 0 & 0 & 0 \\
0 & 1 & 0 & 0 & 0 & 0 & 0 & 0 & 0 & 0 & 0 & 0 \\
0 & 0 & 1 & 0 & 0 & 0 & 0 & 0 & 0 & 0 & 0 & 0 \\
0 & 0 & 0 & 0 & 0 & 0 & 0 & 0 & 0 & 0 & 0 & 1 \\
0 & 0 & 0 & 0 & 1 & 0 & 0 & 0 & 0 & 0 & 0 & 0 \\
0 & 0 & 0 & 0 & 0 & 0 & 0 & 0 & 0 & 0 & 0 & 0 \\
0 & 0 & 0 & 0 & 0 & 0 & 0 & \rho & 0 & 0 & 0 & 0 \\
-\tilde{\alpha}_{\pi 1} & -\tilde{\alpha}_{\pi 2} & -\tilde{\alpha}_{\pi 3} & -\tilde{\alpha}_{\pi 4} & -\alpha_{y} & 0 & 0 & 0 & -\mu_{\pi} / 4 & -\mu_{\pi} / 4 & 1-\mu_{\pi} / 4 & 0 \\
0 & 0 & 0 & 0 & 0 & 0 & 0 & 0 & 1 & 0 & 0 & 0 \\
0 & 0 & 0 & 0 & 0 & 0 & 0 & 0 & 0 & 1 & 0 & 0 \\
0 & 0 & 0 & 0 & -\tilde{\beta}_{y 1} & -\tilde{\beta}_{y 2} & 0 & 0 & -\beta_{r} / 4 & -\beta_{r} / 4 & -\beta_{r} / 4 & 1
\end{array}\right] \\
& B_{1}=\left[\begin{array}{llll}
\mathbf{0}_{6 \times 1}^{\prime} & 1 & \mathbf{0}_{4 \times 1}^{\prime} & \beta_{r}
\end{array}\right]^{\prime},
\end{aligned}
$$

where $\tilde{\alpha}_{\pi j}=\left(1-\mu_{\pi}\right) \alpha_{\pi j} ; \tilde{\beta}_{y j}=\left(1-\mu_{y}\right) \beta_{y j}$; and the shock vector $v_{1 t}$ has covariance matrix $\Sigma$, which is a diagonal matrix with diagonal $\left\{\sigma_{\varepsilon}^{2}, \mathbf{0}_{3 \times 1}, \sigma_{\eta}^{2}, \mathbf{0}_{2 \times 1}, \sigma_{\zeta}^{2}\right\}$ with all off-diagonal elements being zero.

To obtain the usual state-space form, premultiply (A10) by $A_{0}^{-1}$ to get

$$
\left[\begin{array}{c}
x_{1 t+1} \\
\mathrm{E}_{t} x_{2 t+1}
\end{array}\right]=A\left[\begin{array}{c}
x_{1 t} \\
x_{2 t}
\end{array}\right]+B i_{t}+v_{t+1},
$$

where $A=A_{0}^{-1} A_{1}$ and $B=A_{0}^{-1} B_{1}{ }^{17}$

\footnotetext{
${ }^{17}$ Note that this means that we must have $\mu_{\pi}, \mu_{y}>0$, and also that $A_{0}^{-1} v_{t+1}=v_{t+1}$ since $A_{0}$ is block diagonal with an identity matrix as its upper left block and the lower block of $v_{t+1}$ is zero.
} 
To write the central bank's objective function (4), it is convenient to define an $\left(n_{z} \times 1\right)$ vector of target variables $\left(n_{z}=3\right)$ as

$$
z_{t}=\left\{\bar{\pi}_{t}-\pi_{t}^{*}, y_{t}, \Delta i_{t}\right\}^{\prime}
$$

which can be constructed by

$$
z_{t}=C_{x} x_{t}+C_{i} i_{t}
$$

where

$$
\begin{aligned}
C_{x} & =\left[\begin{array}{cccccccccccc}
1 / 4 & 1 / 4 & 1 / 4 & 1 / 4 & 0 & 0 & 0 & -1 & 0 & 0 & 0 & 0 \\
0 & 0 & 0 & 0 & 1 & 0 & 0 & 0 & 0 & 0 & 0 & 0 \\
0 & 0 & 0 & 0 & 0 & 0 & -1 & 0 & 0 & 0 & 0 & 0
\end{array}\right], \\
C_{i} & =\left[\begin{array}{lll}
0 & 0 & 1
\end{array}\right]^{\prime} .
\end{aligned}
$$

\section{A.2 Optimal policy rules}

The central bank's period loss function in (4) can then be written as

$$
\begin{aligned}
L_{t} & =\left(\bar{\pi}_{t}-\pi_{t}^{*}\right)^{2}+\lambda y_{t}^{2}+\nu\left(\Delta i_{t}\right)^{2} \\
& =z_{t}^{\prime} K z_{t}
\end{aligned}
$$

where $K$ is a matrix of preference parameters with diagonal $\{1, \lambda, \nu\}$. Using (A17), the loss function is

$$
\begin{aligned}
L_{t} & =z_{t}^{\prime} K z_{t} \\
& =\left[\begin{array}{ll}
x_{t}^{\prime} & i_{t}^{\prime}
\end{array}\right]\left[\begin{array}{c}
C_{x}^{\prime} \\
C_{i}^{\prime}
\end{array}\right] K\left[\begin{array}{ll}
C_{x} & C_{i}
\end{array}\right]\left[\begin{array}{c}
x_{t} \\
i_{t}
\end{array}\right] \\
& =x_{t}^{\prime} C_{x}^{\prime} K C_{x} x_{t}+x_{t}^{\prime} C_{x}^{\prime} K C_{i} i_{t}+i_{t}^{\prime} C_{i}^{\prime} K C_{x} x_{t}+i_{t}^{\prime} C_{i}^{\prime} K C_{i} i_{t} \\
& \equiv x_{t}^{\prime} Q x_{t}+x_{t}^{\prime} U i_{t}+i_{t}^{\prime} U^{\prime} x_{t}+i_{t}^{\prime} R i_{t},
\end{aligned}
$$

where

$$
x_{t}=\left[\begin{array}{l}
x_{1 t} \\
x_{2 t}
\end{array}\right],
$$

and where

$$
\begin{aligned}
Q & \equiv C_{x}^{\prime} K C_{x} \\
U & \equiv C_{x}^{\prime} K C_{i} \\
R & \equiv C_{i}^{\prime} K C_{i} .
\end{aligned}
$$


Thus the central bank's control problem is given by the conventional Bellman equation

$$
J\left(x_{t}\right)=\min _{i_{t}}\left\{x_{t}^{\prime} Q x_{t}+x_{t}^{\prime} U i_{t}+i_{t}^{\prime} U^{\prime} x_{t}+i_{t}^{\prime} R i_{t}+\delta \mathrm{E}_{t} J\left(x_{t+1}\right)\right\}
$$

subject to the transition equation (A15), and optimal policy rules etc. can be calculated using standard methods (see Söderlind, 1999, for an overview).

The optimal policy under discretion is a rule for the interest rate as a linear function of the predetermined variables:

$$
i_{t}=F_{d} x_{1 t}
$$

resulting in the reduced form

$$
\begin{aligned}
x_{1 t+1} & =M_{d} x_{1 t}+v_{1 t+1}, \\
x_{2 t} & =N_{d} x_{1 t} .
\end{aligned}
$$

\section{B Responses to an interest rate shock}

In order to model a monetary policy shock, i.e., a one-time shock to the interest rate, suppose the central bank changes the interest rate at time $t=0$ by $d i_{t}$, and from then on follows its optimal policy rule $i_{t}=F x_{1 t}$ for all $t>0$. How does the economy respond to such a shock?

Note first that the predetermined variables in $x_{1 t}$ do not respond to a change in $i_{t}$, so $d x_{1 t}=0$. The forward-looking variables in $x_{2 t}$, on the other hand, respond immediately. But the response of $x_{2 t}$ depends on the response of $\mathrm{E}_{t} x_{2 t+1}$. Partition $A$ and $B$ conformably with $x_{1 t}$ and $x_{2 t}$. Then the response of $\mathrm{E}_{t} x_{2 t+1}$ is, using (A29) and (A15),

$$
\begin{aligned}
d \mathrm{E}_{t} x_{2 t+1} & =N d \mathrm{E}_{t} x_{1 t+1} \\
& =N\left[A_{11} d x_{1 t}+A_{12} d x_{2 t}+B_{1} d i_{t}\right] .
\end{aligned}
$$

From (A15) we also get

$$
d \mathrm{E}_{t} x_{2 t+1}=A_{21} d x_{1 t}+A_{22} d x_{2 t}+B_{2} d i_{t} .
$$

Combining these expressions and using $d x_{1 t}=0$ we get

$$
d x_{2 t}=\left[A_{22}-N A_{12}\right]^{-1}\left[N B_{1}-B_{2}\right] d i_{t} .
$$


The variables in $x_{1 t+1}$ then respond by

$$
\begin{aligned}
d x_{1 t+1} & =A_{12} d x_{2 t}+B_{1} d i_{t} \\
& =\left\{A_{12}\left[A_{22}-N A_{12}\right]^{-1}\left[N B_{1}-B_{2}\right]+B_{1}\right\} d i_{t}
\end{aligned}
$$

and from then on the system follows (A28) and (A29). 


\section{References}

Battellino, Ric, John Broadbent, and Philip Lowe, "The implementation of monetary policy in Australia," in Implementation and Tactics of Monetary Policy, Bank for International Settlements, Basel, March 1997.

Buttiglione, Luigi, Paolo Del Giovane, and Eugenio Gaiotti, "Implementation of monetary policy in Italy: The role of repo operations and official rates," in Implementation and Tactics of Monetary Policy, Bank for International Settlements, Basel, March 1997.

Dennis, Richard, "The policy preferences of the U.S. Federal Reserve," Working Paper No. 2001-08, Federal Reserve Bank of San Francisco, July 2001.

Ellingsen, Tore and Ulf Söderström, "Monetary policy and market interest rates," American Economic Review 91 (5), 1594-1607, December 2001.

"Monetary policy and the bond market," Manuscript, Stockholm School of Economics and Università Bocconi, August 2003.

Evans, Charles L. and David A. Marshall, "Monetary policy and the term structure of nominal interest rates: Evidence and theory," Carnegie-Rochester Conference Series on Public Policy 49 (1), 53-111, November 1998.

, "Economic determinants of the nominal Treasury yield curve," Manuscript, Federal Reserve Bank of Chicago, September 2002.

Faust, Jon, Eric Swanson, and Jonathan Wright, "Does the Fed possess inside information about the economy?" Manuscript, Board of Governors of the Federal Reserve System, June 2002.

Fuhrer, Jeffrey C. and Glenn D. Rudebusch, "Estimating the Euler equation for output," Working Paper No. 2002-12, Federal Reserve Bank of San Francisco, September 2002. Forthcoming, Journal of Monetary Economics.

Gürkaynak, Refet S., Brian Sack, and Eric Swanson, "The excess sensitivity of long-term interest rates: Evidence and implications for macroeconomic models," Finance and Economics Discussion Paper No. 2003-50, Board of Governors of the Federal Reserve System, November 2003.

Kuttner, Kenneth N., "Monetary policy surprises and interest rates: Evidence from the fed funds futures market," Journal of Monetary Economics 47 (3), 523-544, June 2001.

Lindberg, Hans, Kerstin Mitlid, and Peter Sellin, "Monetary tactics with an inflation target: The Swedish case," in Implementation and Tactics of Monetary Policy, Bank for International Settlements, Basel, March 1997. 
Peek, Joe, Eric S. Rosengren, and Geoffrey M. B. Tootell, "Is bank supervision central to central banking?" Quarterly Journal of Economics 114 (2), 629-655, May 1999.

- "Does the Federal Reserve possess an exploitable informational advantage?" Journal of Monetary Economics 50 (4), 817-839, May 2003.

Peersman, Gert, "Monetary policy and long term interest rates in Germany," Economics Letters 77 (2), 271-277, October 2002.

Rigobon, Roberto and Brian Sack, "The impact of monetary policy on asset prices," Working Paper No. 8794, National Bureau of Economic Research, February 2002.

Romer, Christina D. and David H. Romer, "Federal Reserve information and the behavior of interest rates," American Economic Review 90 (3), 429-457, June 2000 .

Rudebusch, Glenn D., "Assessing nominal income rules for monetary policy with model and data uncertainty," Economic Journal 112 (479), 1-31, April 2002.

Söderlind, Paul, "Solution and estimation of RE macromodels with optimal policy," European Economic Review Papers and Proceedings 43 (4-6), 813-823, April 1999.

Söderström, Ulf, Paul Söderlind, and Anders Vredin, "New-Keynesian models and monetary policy: A reexamination of the stylized facts," Manuscript, Università Bocconi, Universität St. Gallen and Sveriges Riksbank, August 2003. Revised version of Sveriges Riksbank Working Paper No. 140.

Svensson, Lars E. O., "Inflation forecast targeting: Implementing and monitoring inflation targets," European Economic Review 41 (6), 1111-1146, June 1997. 
Figure 1: Estimated yield curve response to a monetary policy innovation

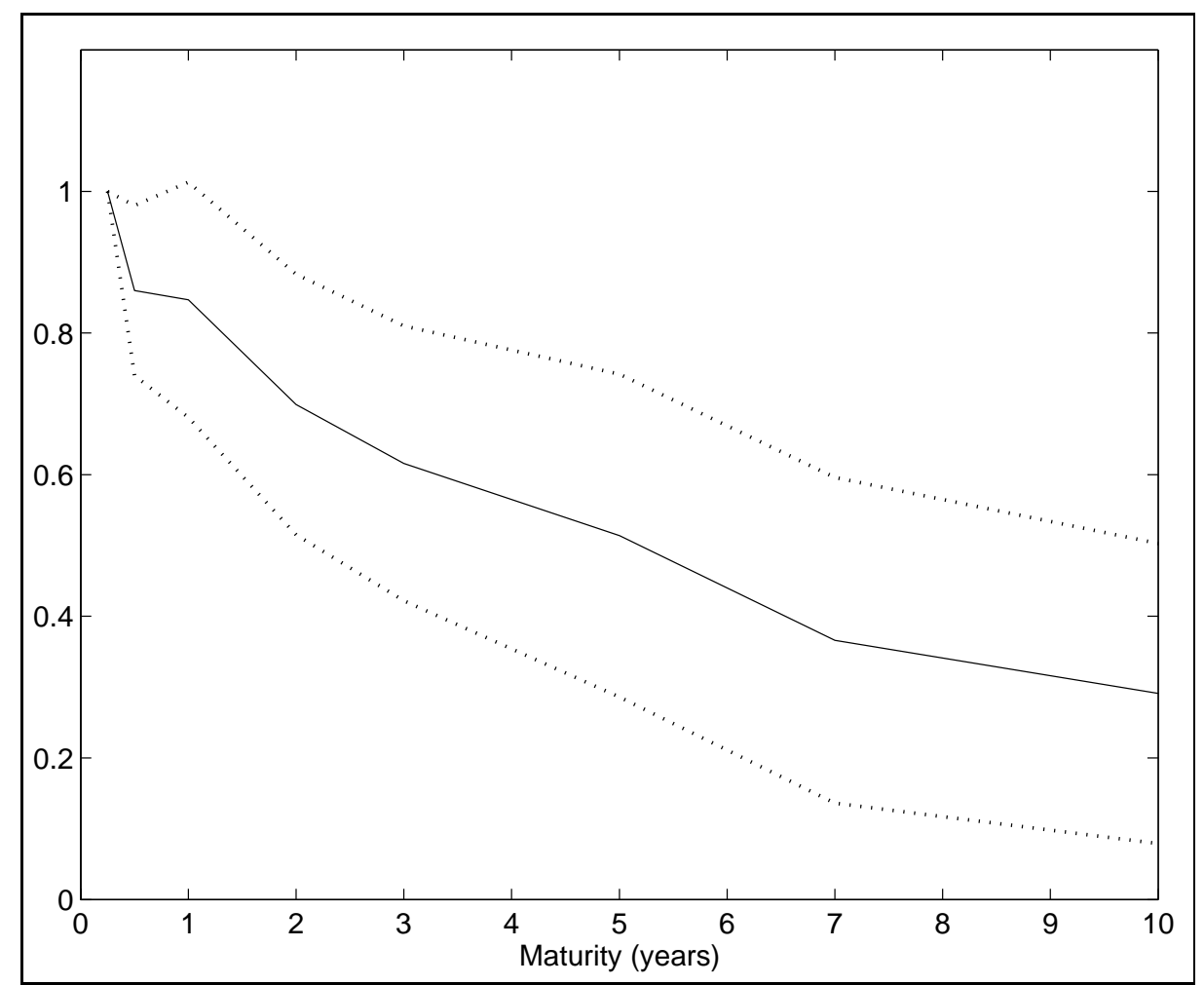

Note: The figure shows the estimated response of the yield curve to changes in the 3-month T-bill rate on all dates when the federal funds rate target was adjusted from October 1988 to December 2001. The dotted lines are two standard-error confidence intervals. 
Figure 2: Policy and yield curve response to policy innovation

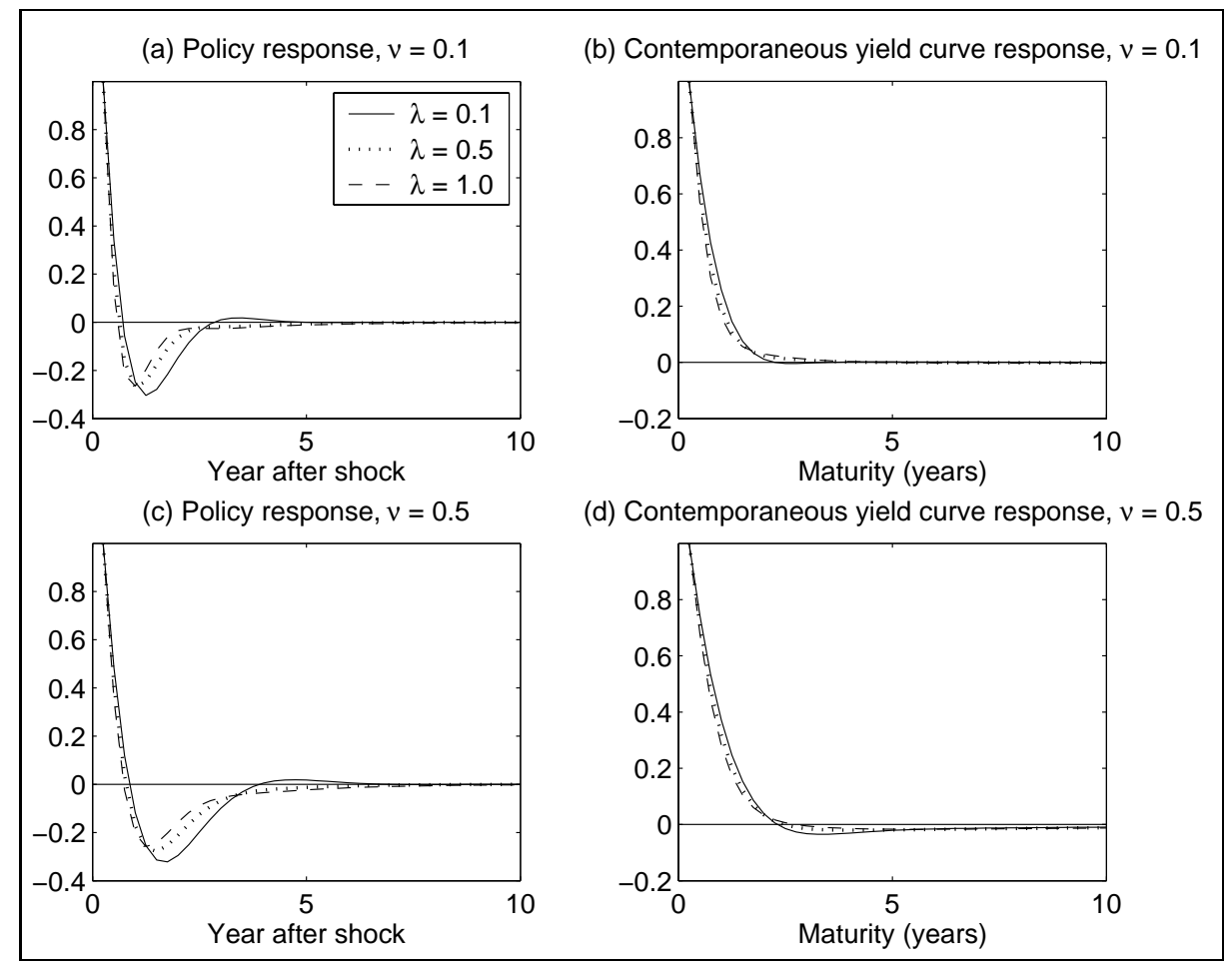

Note: Panels $(a)$ and $(c)$ show the response of the short-term interest rate (the monetary policy instrument) to a one percentage point unexpected increase in the short rate, after which policy is expected to follow the optimal rule under discretion. (See Appendix B for details.) Panels $(b)$ and $(d)$ show the implied contemporaneous response of the yield curve. 
Figure 3: Estimated yield curve response to monetary policy innovations

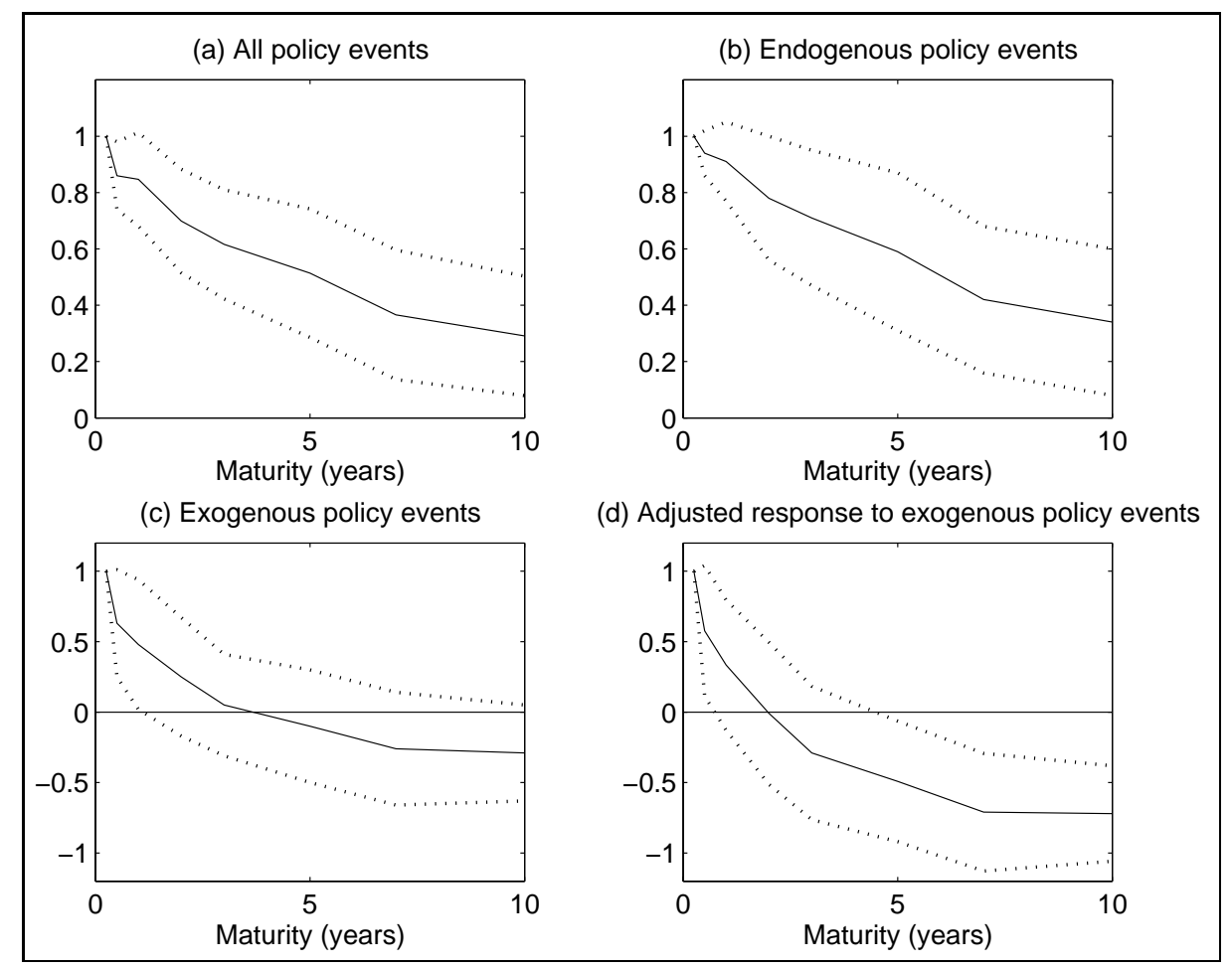

Note: Panel $(a)$ shows the estimated response of the yield curve to changes in the 3-month T-bill rate on all dates when the federal funds rate target was adjusted from October 1988 to December 2001. Panels $(b)-(d)$ show the estimated response on dates classified as exogenous and endogenous (see Ellingsen and Söderström, 2003, for details). The dotted lines are two standard-error confidence intervals. 
Figure 4: Policy response to shocks

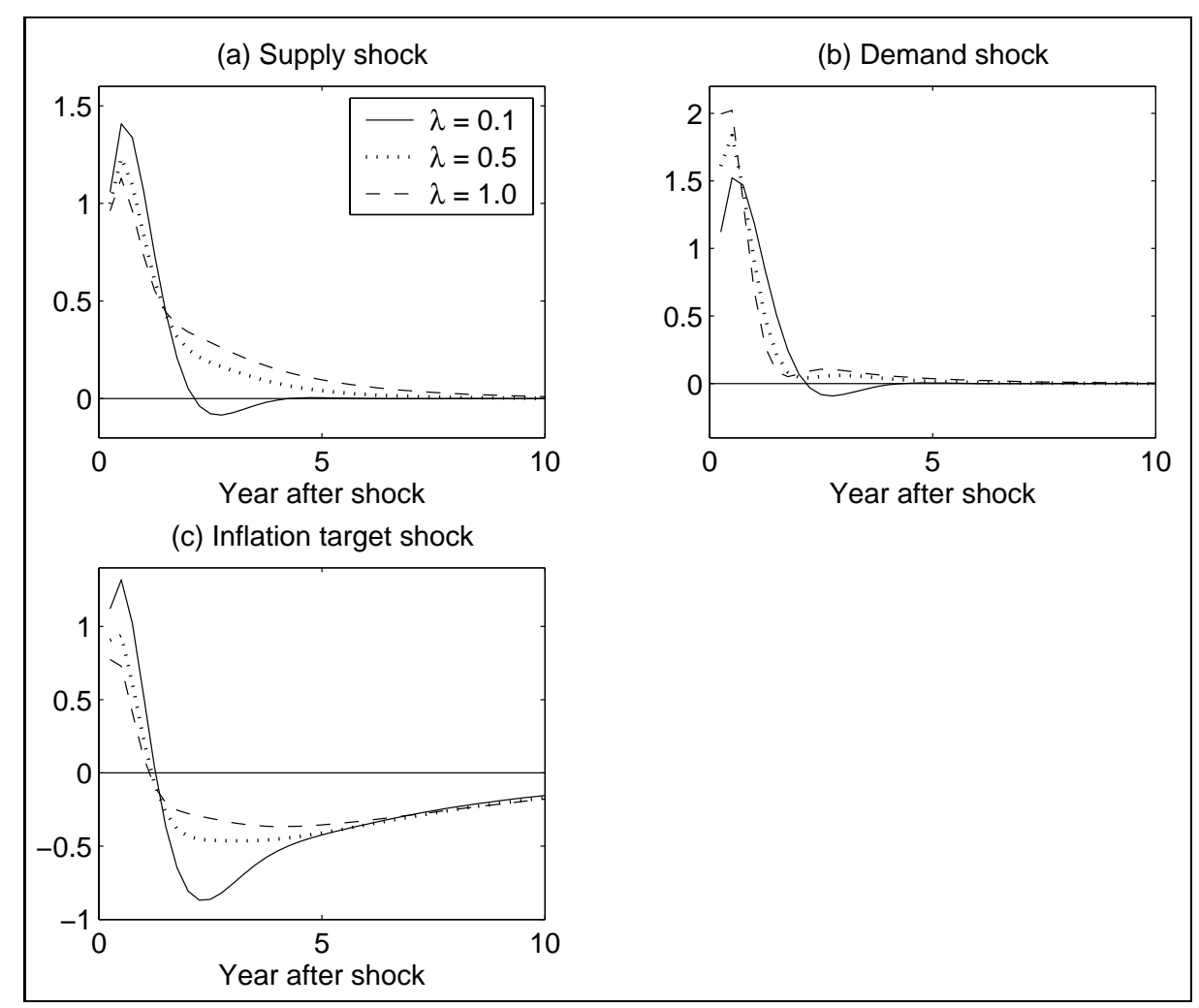

Note: Panels $(a)$ and $(b)$ show the response over time of the short-term interest rate (the monetary policy instrument) to positive one percentage point shocks to inflation $\left(\varepsilon_{t}\right)$ and output $\left(\eta_{t}\right)$. Panel $(c)$ shows the response of the short-term interest rate to a negative one percentage point shock to the inflation target $\left(\zeta_{t}\right)$. 
Figure 5: Contemporaneous yield curve response to shocks

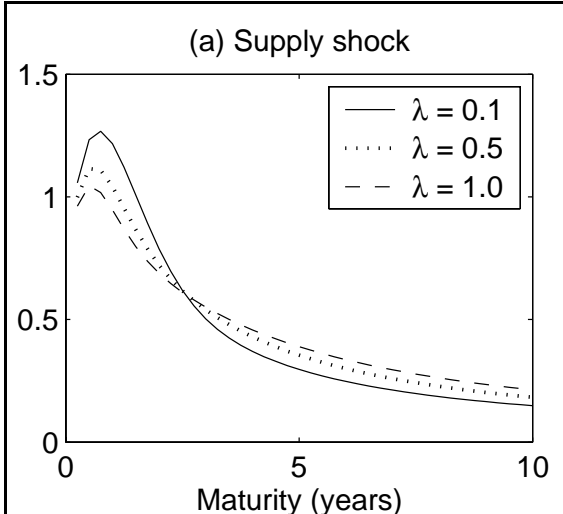

(b) Demand shock

(c) Inflation target shock
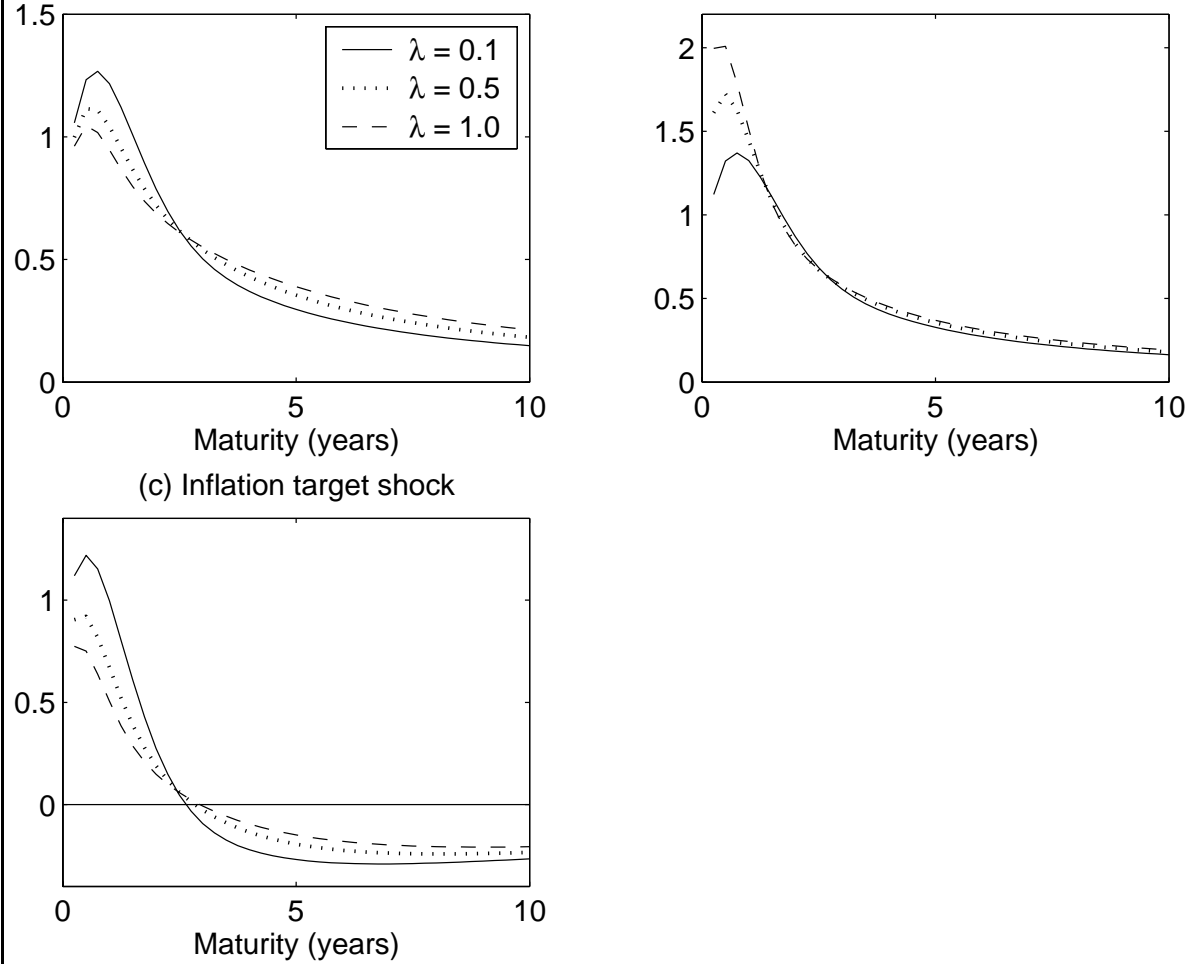

Note: Panels $(a)$ and $(b)$ show the contemporaneous response of the yield curve to positive one percentage point shocks to inflation $\left(\varepsilon_{t}\right)$ and output $\left(\eta_{t}\right)$. Panel $(c)$ shows the contemporaneous response of the yield curve to a negative one percentage point shock to the inflation target $\left(\zeta_{t}\right)$. 
Figure 6: Yield curve response to endogenous and exogenous policy

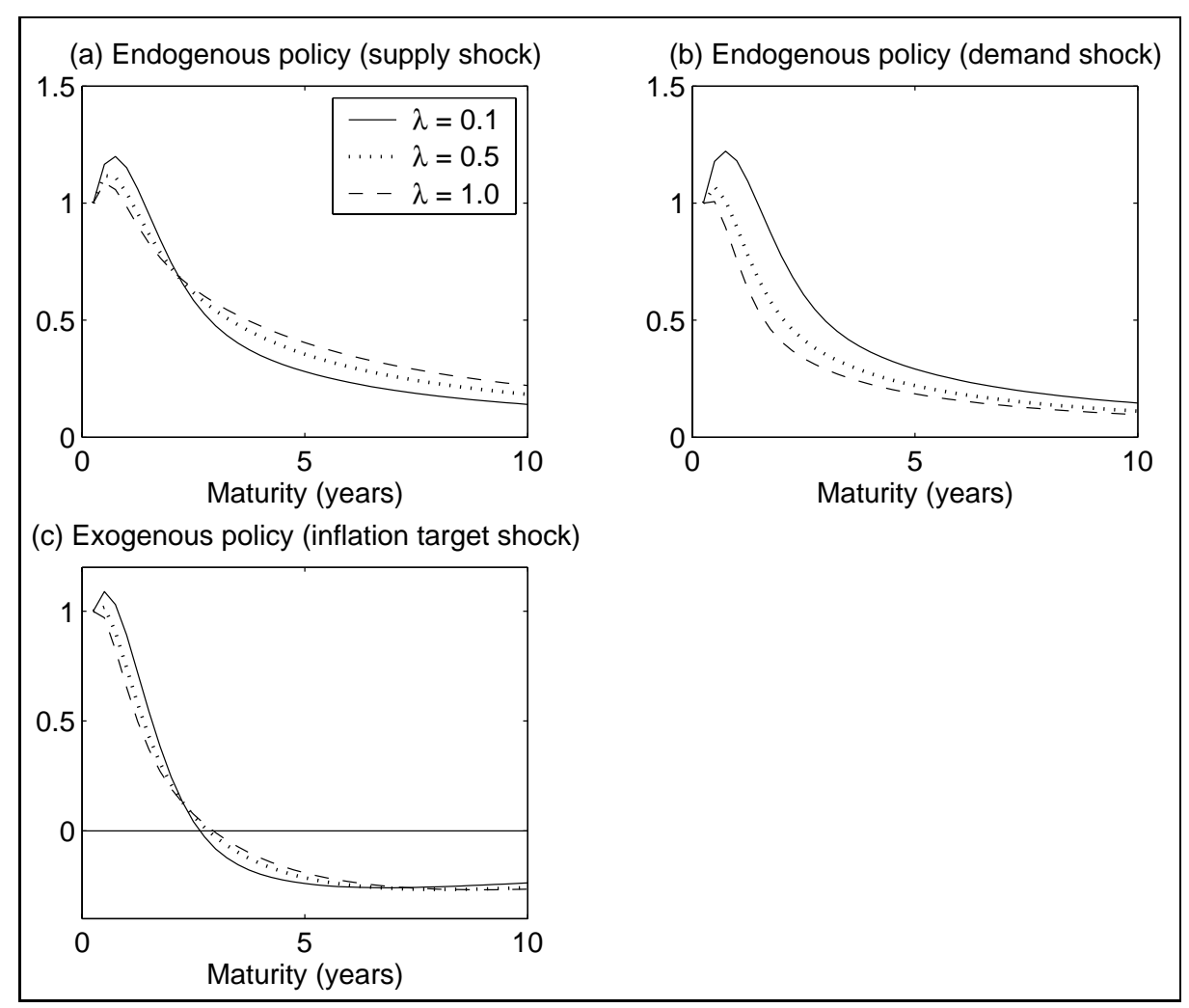

Note: Panels $(a)$ and $(b)$ show the contemporaneous response of the yield curve to an unexpected one percentage point increase in the short-term interest rate, interpreted as a response to an unobserved shock to inflation or output. Panel $(c)$ shows the contemporaneous response of the yield curve to an unexpected one percentage point increase in the short-term interest rate, interpreted as an unobserved decrease in the central bank's inflation target. 
Figure 7: Estimated and model yield curve response

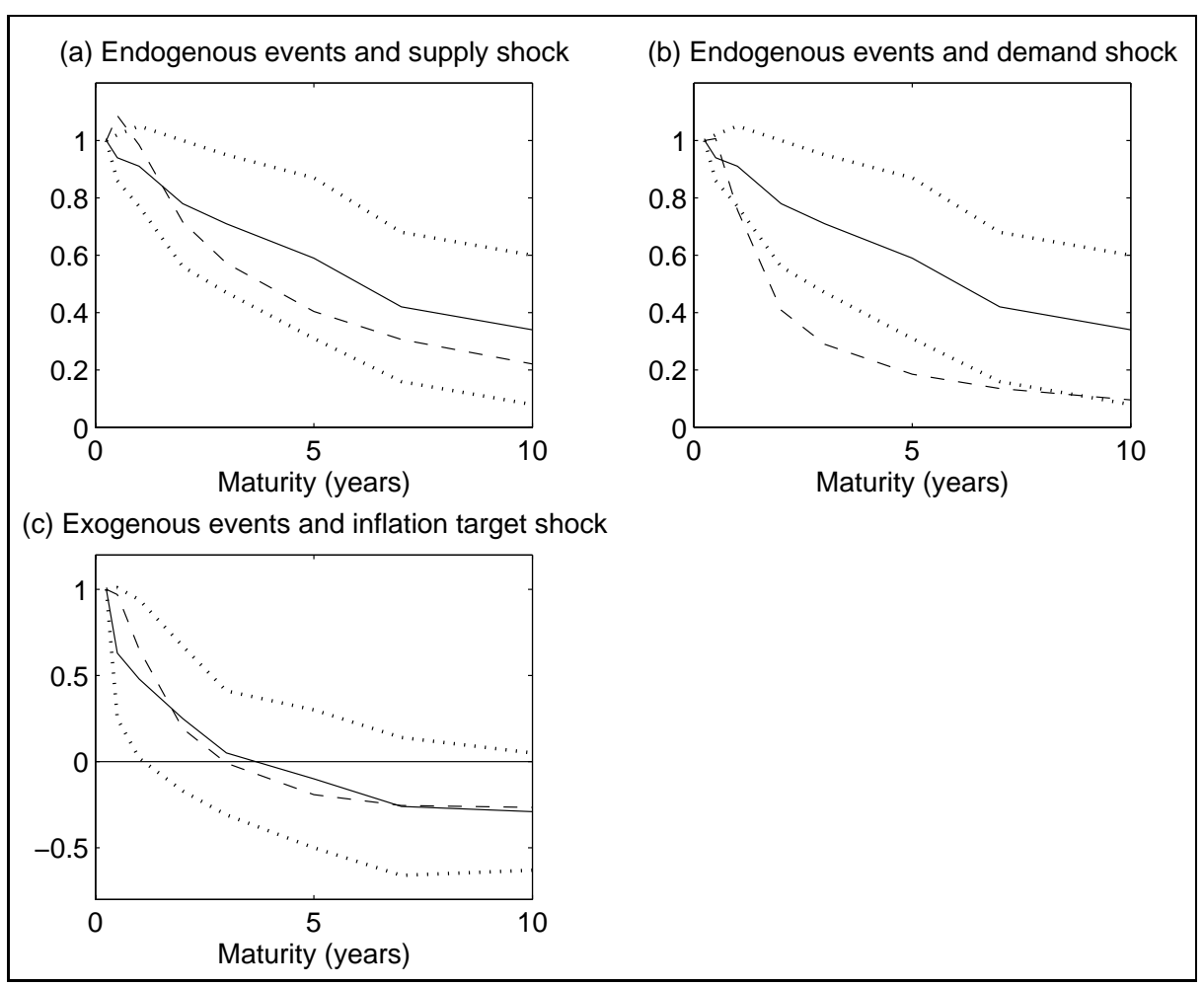

Note: The figure shows the estimated yield curve response to endogenous and exogenous policy events (the solid lines) from Figure 3, panels $(b)$ and $(c)$, along with the yield curve response in the model (the dashed lines) from Figure 6 (with $\lambda=1.0$ ). The dotted lines are two standard-error confidence intervals around the estimated response. 
Figure 8: Yield curve response to exogenous shifts in the central bank preference for output stabilization

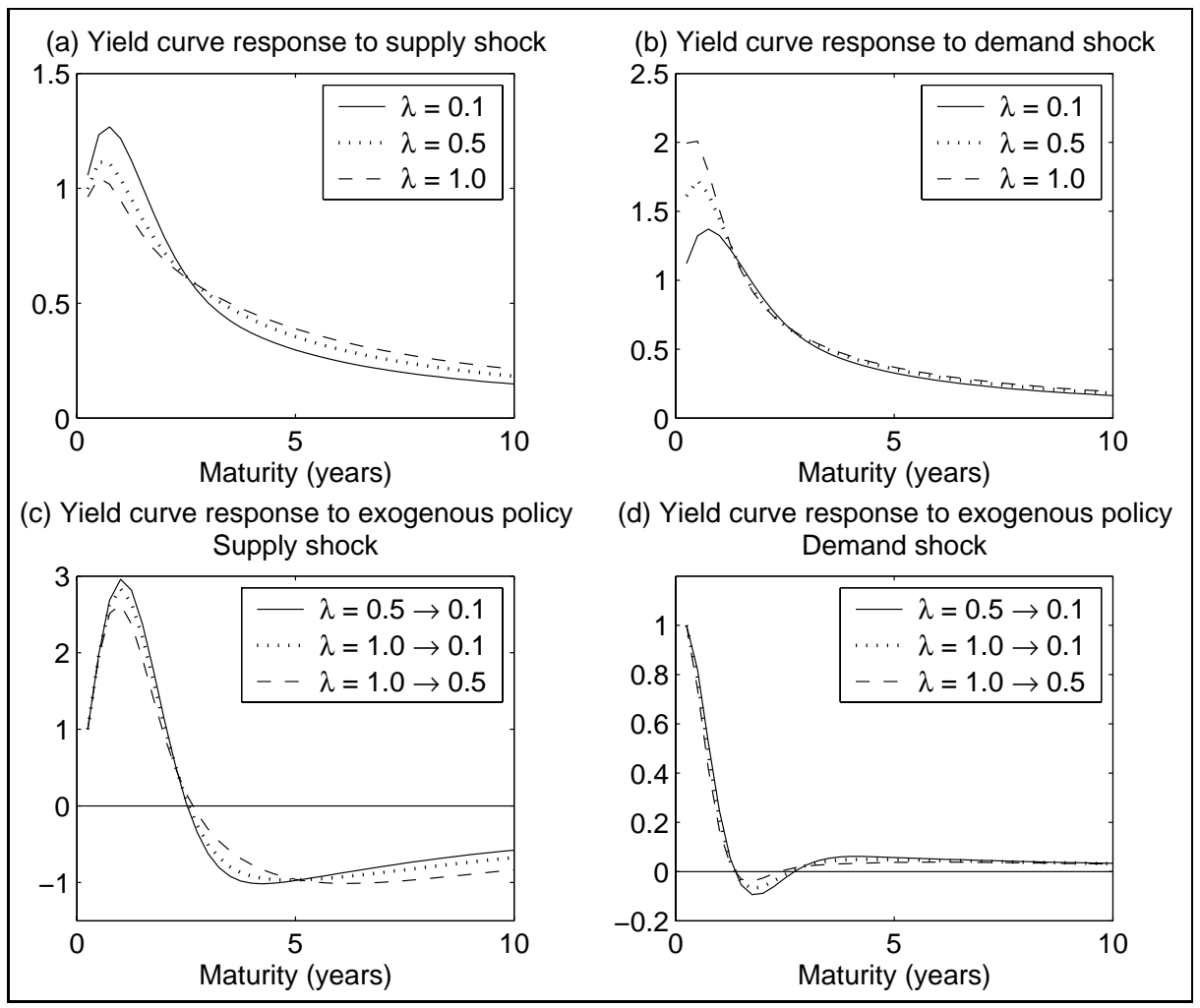

Note: Panels $(a)$ and $(b)$ show the contemporaneous response of the yield curve to positive one percentage point shocks to inflation $\left(\varepsilon_{t}\right)$ and output $\left(\eta_{t}\right)$, taken from Figure 5, panels $(a)$ and $(b)$. Panels $(c)$ and $(d)$ show the implied contemporaneous response of the yield curve to an unexpected one percentage point increase in the short-term interest rate, interpreted as a change in the central bank's weight on output stabilization $(\lambda)$ after shocks to inflation and output. 
Figure 9: Yield curve response to endogenous policy (supply shock) for different $\lambda$ and $\nu$

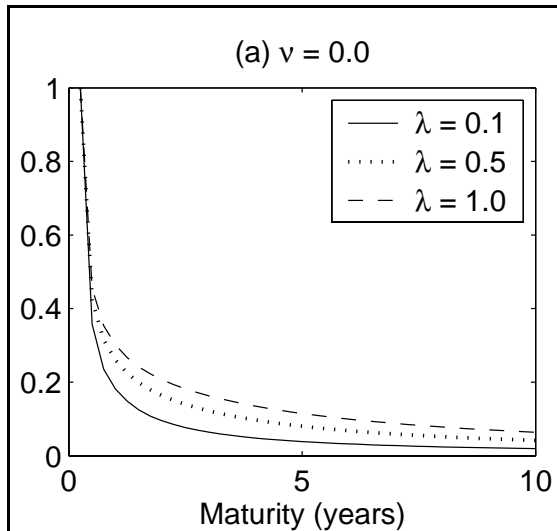

(c) $v=0.5$

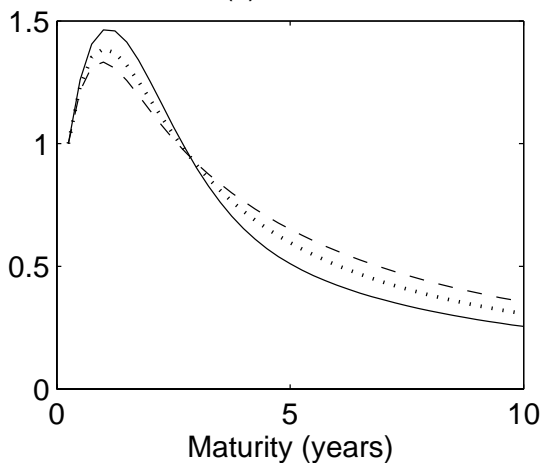

(b) $v=0.1$

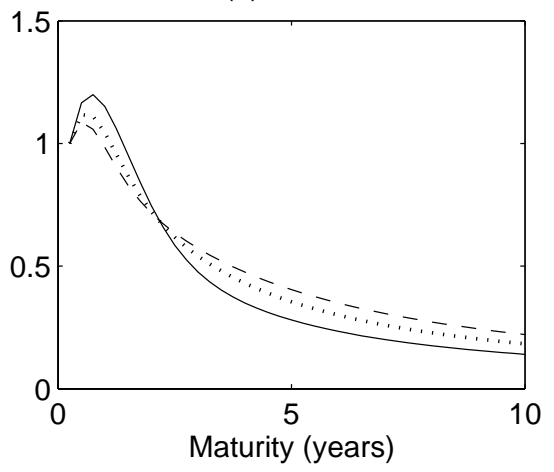

(d) $v=1.0$

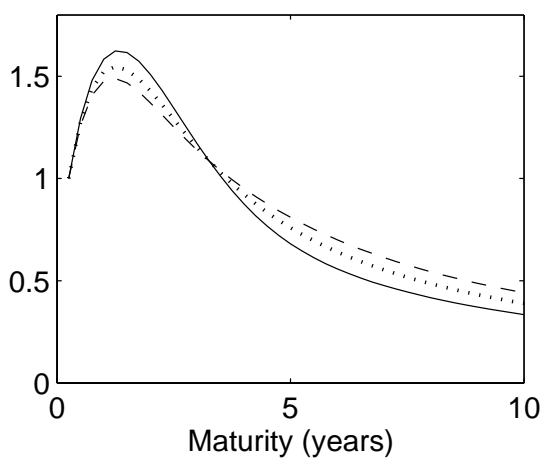

Note: The figure shows the contemporaneous response of the yield curve to an unexpected one percentage point increase in the short-term interest rate, interpreted as a response to an unobserved shock to inflation, for different central bank preferences for output stability $(\lambda)$ and interest rate smoothing $(\nu)$. 
Figure 10: Yield curve response to endogenous policy (demand shock) for different $\lambda$ and $\nu$

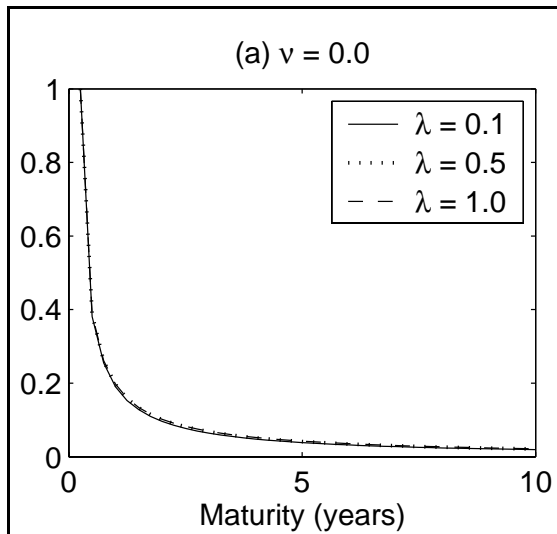

(c) $v=0.5$

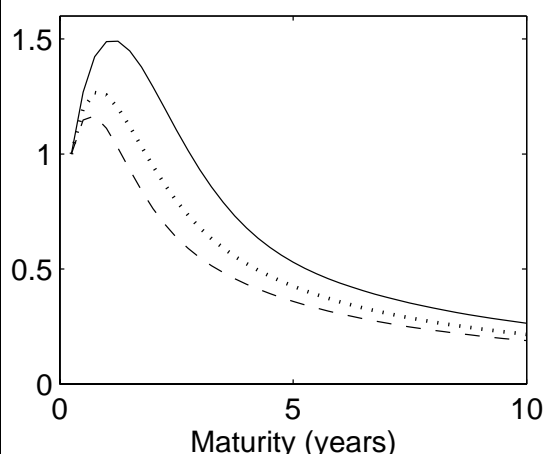

(b) $v=0.1$

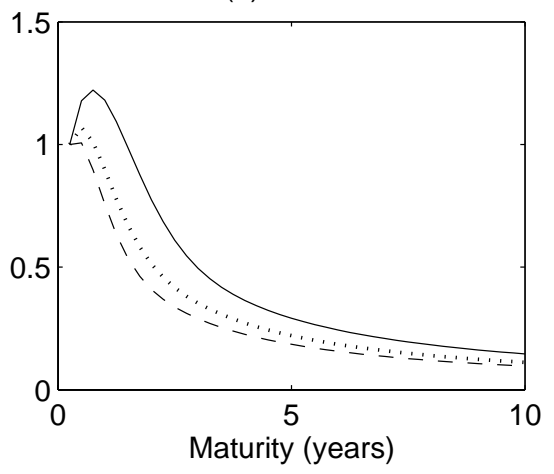

(d) $v=1.0$

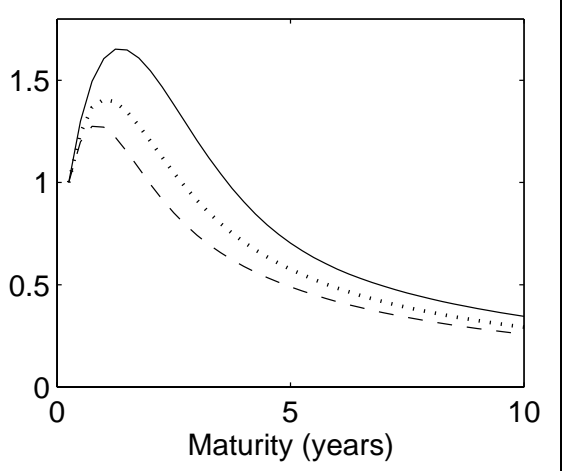

Note: The figure shows the contemporaneous response of the yield curve to an unexpected one percentage point increase in the short-term interest rate, interpreted as a response to an unobserved shock to output, for different central bank preferences for output stability $(\lambda)$ and interest rate smoothing $(\nu)$. 
Figure 11: Yield curve response to exogenous policy for different $\nu$ and $\rho$

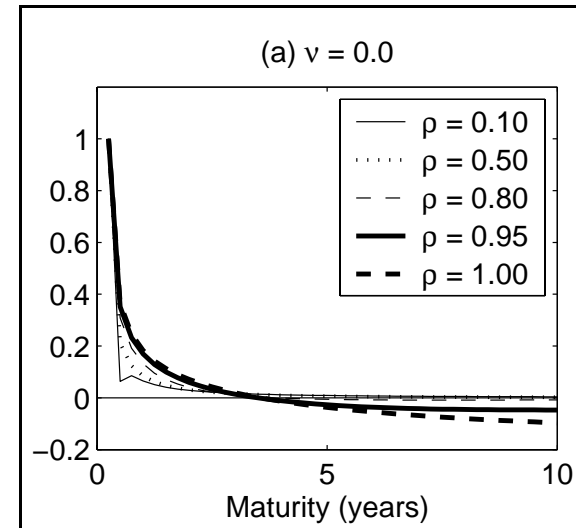

(c) $v=0.5$

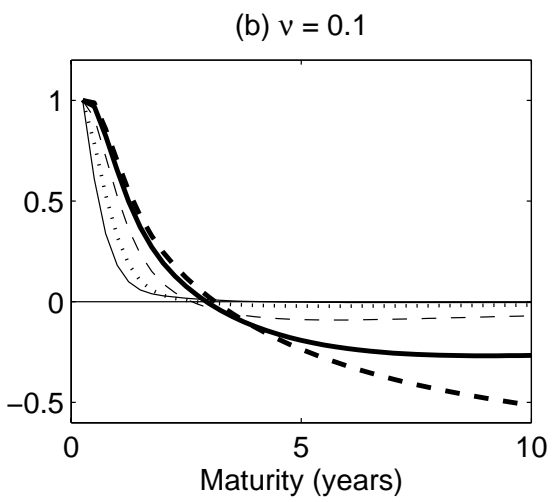

(d) $v=1.0$
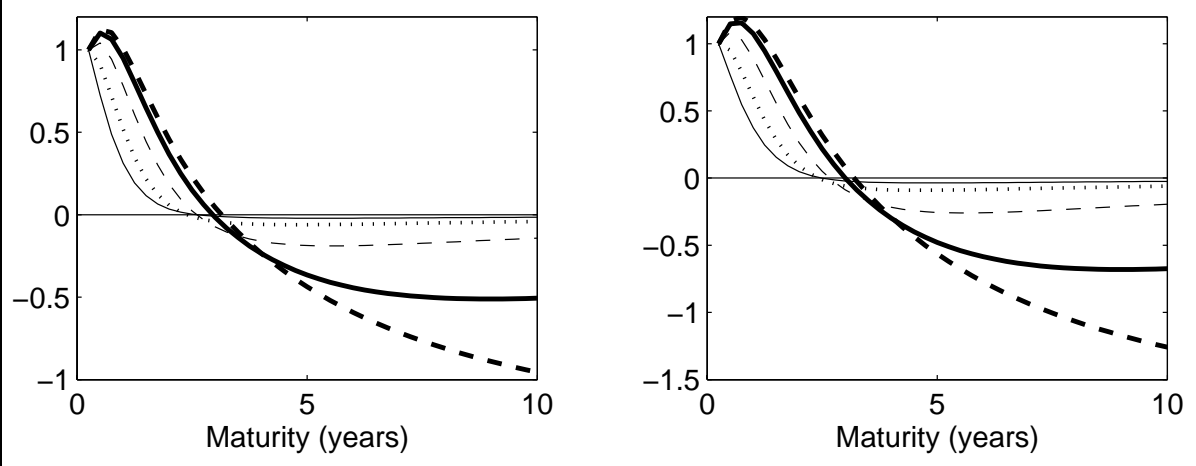

Note: The figure shows the contemporaneous response of the yield curve to an unexpected one percentage point increase in the short-term interest rate, interpreted as a response to an unobserved shock to the inflation target, for different central bank preferences for interest rate smoothing $(\nu)$ and persistence in the inflation target $(\rho)$. The preference for output stabilization is set to $\lambda=1.0$. 


\section{Earlier Working Papers:}

Inflation Forecast Targeting: the Swedish Experience by Claes Berg . 2000:100

Wage Effects of Mobility, Unemployment Benefits and Benefit Financing

by Hans Lindblad. 2000:101

A Bivariate Distribution for Inflation and Output Forecasts

by Mårten Blix and Peter Sellin .... 2000:102

Optimal Horizons for Inflation Targeting

by Nicoletta Batini and Edward Nelson. 2000:103

Empirical Estimation and the Quarterly Projection Model:

An Example Focusing on the External Sector

by Robert Amano, Don Coletti and Stephen Murchison

Conduction Monetary Policy with a Collegial Bord:

The New Swedish Legislation One Year On by Claes Berg and Hans Lindberg

Price-level targeting versus inflation targeting in a forward-looking model

by David Vestin

Unemployment and Inflation Regimes by Anders Vredin and Anders Warne 2000:107

An Expectations-Augmented Phillips Curve in an Open Economy by Kerstin Hallsten 2000:108

An alternative interpretation of the recent U.S. inflation performance

by Mikael Apel and Per Jansson.... 2000:109

Core inflation and monetary policy by Marianne Nessén and UIf Söderström 2000:110

Estimating the Implied Distribution of the Future Short-Term Interest Rate

Using the Longstaff-Schwartz Model by Peter Hördahl. 2000:111

Financial Variables and the Conduct of Monetary Policy

by Charles Goodhart and Boris Hofmann

Testing for the Lucas Critique: A Quantitative Investigation by Jesper Lindé ................................. 2000:113

Monetary Policy Analysis in Backward-Looking Models by Jesper Lindé....................................... 2000:114

UIP for short investments in long-term bonds by Annika Alexius ................................................. 2000:115

Qualitative Survey Responses and Production over the Business Cycle

by Tomas Lindström

Supply stocks and real exchange rates by Annika Alexius ..................................................... 2000:117

Casuality and Regime Inference in a Markov Switching VAR by Anders Warne ........................... 2000:118

Average Inflation Targeting by Marianne Nessén and David Vestin ............................................ 2000:119

Forecast-based monetary policy in Sweden 1992-1998: A view from within

by Per Jansson and Anders Vredin ......................................................................... 2000:120

What have we learned from empirical tests of the monetary transmission effect?

by Stefan Norrbin

Simple monetary policy rules and exchange rate uncertainty

by Kai Leitemo and UIf Söderström

Targeting inflation with a prominent role for money

by Ulf Söderström

Is the Short-run Phillips Curve Nonlinear? Empirical Evidence for Australia, Sweden

and the United States by Ann-Charlotte Eliasson

An Alternative Explanation of the Price Puzzle by Paolo Giordani ............................................. 2001:125

Interoperability and Network Externalities in Electronic Payments by Gabriela Guibourg................ 2001:126

Monetary Policy with Incomplete Exchange Rate Pass-Through by Malin Adolfson ...................... 2001:127

Micro Foundations of Macroeconomic Price Adjustment: Survey Evidence from

Swedish Firms by Mikael Apel, Richard Friberg and Kerstin Hallsten....

Estimating New-Keynesian Phillips Curves on Data with Measurement Errors:

A Full Information Maximum Likelihood Approach by Jesper Lindé

The Empirical Relevance of Simple Forward- and Backward-looking Models:

A View from a Dynamic General Equilibrium Model by Jesper Lindé

Diversification and Delegation in Firms by Vittoria Cerasi and Sonja Daltung 2001:131

Monetary Policy Signaling and Movements in the Swedish Term Structure of Interest Rates

by Malin Andersson, Hans Dillén and Peter Sellin ....

Evaluation of exchange rate forecasts for the krona's nominal effective exchange rate by Henrik Degrér, Jan Hansen and Peter Sellin .... 
Implications of Exchange Rate Objectives under Incomplete Exchange Rate Pass-Through by Malin Adolfson

Incomplete Exchange Pass-Through and Simple Monetary Policy Rules

by Malin Adolfson

Financial Instability and Monetary Policy: The Swedish Evidence

by U. Michael Bergman and Jan Hansen

Finding Good Predictors for Inflation: A Bayesian Model Averaging Approach

by Tor Jacobson and Sune Karlsson

How Important Is Precommitment for Monetary Policy?

by Richard Dennis and Ulf Söderström

Can a Calibrated New-Keynesian Model of Monetary Policy Fit the Facts?

by Ulf Söderström, Paul Söderlind and Anders Vredin

Inflation Targeting and the Dynamics of the Transmission Mechanism

by Hans Dillén

Capital Charges under Basel II: Corporate Credit Risk Modelling and the Macro Economy

by Kenneth Carling, Tor Jacobson, Jesper Lindé and Kasper Roszbach .....

Capital Adjustment Patterns in Swedish Manufacturing Firms: What Model Do They Suggest?

by Mikael Carlsson and Stefan Laséen

Bank Lending, Geographical Distance, and Credit risk: An Empirical Assessment

of the Church Tower Principle by Kenneth Carling and Sofia Lundberg

Inflation, Exchange Rates and PPP in a Multivariate Panel Cointegration Model

by Tor Jacobson, Johan Lyhagen, Rolf Larsson and Marianne Nessén

Evaluating Implied RNDs by some New Confidence Interval Estimation Techniques

by Magnus Andersson and Magnus Lomakka

Taylor Rules and the Predictability of Interest Rates

by Paul Söderlind, Ulf Söderström and Anders Vredin

Inflation, Markups and Monetary Policy

by Magnus Jonsson and Stefan Palmqvist

Financial Cycles and Bankruptcies in the Nordic Countries by Jan Hansen .....

Bayes Estimators of the Cointegration Space by Mattias Villani. 2003:150

Business Survey Data: Do They Help in Forecasting the Macro Economy?

by Jesper Hansson, Per Jansson and Mårten Löf....

The Equilibrium Rate of Unemployment and the Real Exchange Rate:

An Unobserved Components System Approach by Hans Lindblad and Peter Sellin 2003:152

Monetary Policy Shocks and Business Cycle Fluctuations in a

Small Open Economy: Sweden 1986-2002 by Jesper Lindé

Bank Lending Policy, Credit Scoring and the Survival of Loans by Kasper Roszbach

Internal Ratings Systems, Implied Credit Risk and the Consistency of Banks' Risk

Classification Policies by Tor Jacobson, Jesper Lindé and Kasper Roszbach

Monetary Policy Analysis in a Small Open Economy using Bayesian Cointegrated

Structural VARs by Mattias Villani and Anders Warne

Indicator Accuracy and Monetary Policy: Is Ignorance Bliss? by Kristoffer P. Nimark

Intersectoral Wage Linkages in Sweden by Kent Friberg

2003:158

Do Higher Wages Cause Inflation? by Magnus Jonsson and Stefan Palmqvist

2004:159 
Sveriges Riksbank

Visiting address: Brunkebergs torg 11

Mail address: se-103 37 Stockholm 